\title{
Development of Diabetes in Japanese Subjects with Impaired Glucose Tolerance: A Seven Year Follow-Up Study
}

\author{
A. Sasaki, T. Suzuki and N. Horiuchi \\ Centre for Adult Diseases, Osaka, Japan
}

\begin{abstract}
Summary. Five hundred and seven subjects with postprandial glycosuria underwent a $50 \mathrm{~g}$ oral glucose tolerance test in an epidemiological survey of diabetes mellitus carried out in 1964-1965 in the town of Osa$\mathrm{ka}$, Japan. The oral glucose tolerance test was repeated 7 years later in $207(40.8 \%)$ of the subjects. The results of the initial and the follow-up test were classified into three categories according to the new WHO criteria: normal, impaired glucose tolerance and diabetes. Most of the diabetic subjects $(84.8 \%)$ remained unchanged between the initial and follow-up test. Of the subjects with impaired glucose tolerance at the time of the initial test, $38.5 \%$ showed diabetes in the follow-up test, while another $38.5 \%$ returned to normal. On the other hand, $13.5 \%$ of the normal subjects in the initial test developed impaired glucose tolerance or diabetes in the follow-up test. The rate of worsening to diabetes was related closely to the $2-\mathrm{h}$ blood glucose value at the initial test. In addition, the rate of worsening was higher in males and obese subjects than in females and non-obese subjects. A multiple logistic analysis indicated that the fasting and 2-h glucose values were significantly predictive of worsening to diabetes.
\end{abstract}

Key words: Diabetes mellitus, glucose tolerance test, impaired glucose tolerance, WHO criteria, worsening to diabetes, epidemiological survey, follow-up study.

Impaired glucose tolerance (IGT) as defined by the WHO Expert Committee [1] (fasting glucose $<7.8 \mathrm{mmol} / 1$ and 2 -h glucose between 7.8 and $11.1 \mathrm{mmol} / \mathrm{l}$ ) is relatively common, especially among those of middle age or over, and presents problems both in its interpretation and in management [2]. The prognosis of subjects with IGT has not been thor- oughly elucidated. An important question is the rate of worsening to diabetes, and therefore long-term follow-up studies are needed. Recently several epidemiological studies have reported results on this matter [2-6]. The new diagnostic criteria for diabetes mellitus proposed by the WHO Expert Committee [1] and the NIH Data Group [7] were based mainly on these findings.

In 1964-1965, we carried out an epidemiological survey on diabetes mellitus in Osaka, Japan $[8,9]$. In the present report, we present the results of a 7 -year follow-up study with an analysis of relation between variables at the initial survey and the subsequent development of diabetes.

\section{Subjects and Methods}

\section{Subjects}

A total of 507 subjects received an oral glucose tolerance test as well as other investigations for cardiovascular complications in an epidemiological survey carried out in 1964-1965 in the town of Osaka, Japan $[8,9]$. Seven years after the initial survey, all subjects were requested to undergo a retest. Two hundred and seven (103 males and 104 females), corresponding to $40.8 \%$ of the original sample, par-

Table 1. Causes of death in 88 subjects who died during the 7 -year period after the initial survey

\begin{tabular}{|c|c|c|c|c|c|c|}
\hline \multirow[t]{3}{*}{ Causes of death } & \multicolumn{6}{|c|}{ Glucose tolerance at the initial survey } \\
\hline & \multicolumn{2}{|c|}{ Normal } & \multicolumn{2}{|c|}{$\begin{array}{l}\text { Impaired } \\
\text { glucose } \\
\text { tolerance }\end{array}$} & \multicolumn{2}{|c|}{ Diabetes } \\
\hline & No. & $\%$ & No. & $\%$ & No. & $\%$ \\
\hline All causes & 54 & 100.0 & 10 & 100.0 & 24 & 100.0 \\
\hline Neoplasms & 11 & 20.3 & 3 & 30.0 & 1 & 4.2 \\
\hline Cardiovascular & 30 & 55.6 & 7 & 70.0 & 17 & 70.8 \\
\hline Others & 13 & 24.1 & - & - & 6 & 25.0 \\
\hline
\end{tabular}


ticipated in the follow-up test. During the 7-year interval, 88 deaths had been reported, and the major causes of death are given in Table 1 .

\section{Oral Glucose Tolerance Test}

A 50-g glucose dose was given orally and blood samples were taken from the antecubital vein before and 1,2 and $3 \mathrm{~h}$ after glucose loading. Serum glucose was determined by the ferricyanide method using an autoanalyzer.

\section{Classification of Subjects}

The results of oral glucose tolerance tests were classified according to the new diagnostic criteria of the WHO [1]: subjects with fasting

Table 2. Number of subjects studied grouped by age, sex and glucose tolerance category at the initial survey

\begin{tabular}{|c|c|c|c|c|c|c|}
\hline \multirow[t]{2}{*}{$\begin{array}{l}\text { Age group } \\
\text { (years) }\end{array}$} & \multicolumn{2}{|c|}{ Normal } & \multicolumn{2}{|c|}{$\begin{array}{l}\text { Impaired } \\
\text { glucose } \\
\text { tolerance }\end{array}$} & \multicolumn{2}{|c|}{ Diabetes } \\
\hline & $\mathbf{M}$ & $\mathrm{F}$ & M & $\mathrm{F}$ & M & $\mathrm{F}$ \\
\hline $0-35$ & 9 & 9 & - & - & - & 1 \\
\hline $35-44$ & 15 & 20 & - & - & 1 & 3 \\
\hline $45-54$ & 21 & 27 & - & 6 & 5 & 3 \\
\hline $55-64$ & 19 & 18 & 4 & 1 & 4 & 8 \\
\hline $65+$ & 20 & 3 & 2 & - & 3 & 5 \\
\hline Total & 84 & 77 & 6 & 7 & 13 & 20 \\
\hline Both sexes & \multicolumn{2}{|c|}{161} & \multicolumn{2}{|c|}{13} & \multicolumn{2}{|c|}{33} \\
\hline Mean age \pm SEM & \multicolumn{2}{|c|}{$50.0 \pm 1.0$} & \multicolumn{2}{|c|}{$57.4 \pm 2.0$} & \multicolumn{2}{|c|}{$55.6 \pm 2.1$} \\
\hline
\end{tabular}

Table 3. Changes in glucose tolerance category after 7 years

\begin{tabular}{lccl}
\hline $\begin{array}{l}\text { Category } \\
\text { of initial test }\end{array}$ & \multicolumn{3}{l}{ Category of follow-up test } \\
\cline { 2 - 4 } & Normal & $\begin{array}{l}\text { Impaired } \\
\text { glucose } \\
\text { tolerance }\end{array}$ & Diabetes \\
\hline Normal $(n=161)$ & $139(86.3)$ & $15(9.3)$ & $7(4.3)$ \\
Impaired glucose & $5(38.5)$ & $3(23.1)$ & $5(38.5)$ \\
tolerance $(n=13)$ & $1(8.3)$ & $4(12.1)$ & $28(84.8)$ \\
Diabetes $(n=33)$ & &
\end{tabular}

Each figure represents the number (percentage) of subjects in the corresponding initial test category who fell into the follow-up test category defined at the head of the column glucose level $\geqq 7.8 \mathrm{mmol} / 1$ or 2 -h glucose level $(2 \mathrm{~h}) \geqq 11.1 \mathrm{mmol} / 1$ or both were called diabetic, subjects with fasting glucose $<7.8 \mathrm{mmol} / 1$ and $2 \mathrm{~h}$ between $7.8-11.1 \mathrm{mmol} / 1$ were termed IGT, and subjects with fasting glucose $<7.8 \mathrm{mmol} / 1$ and $2 \mathrm{~h}$ $<7.8 \mathrm{mmol} / 1$ were classified as normal. The normal subjects were divided further into two subgroups according to whether the 2-h glucose levels were below or above $6.1 \mathrm{mmol} / 1$. Subjects who were normal or had IGT at the initial survey and who became diabetic during the 7-year period were defined as 'worsening to diabetes'. Obesity was defined as body weight in excess of $115 \%$ desirable body weight, using the standard height and weight table for Japanese [10].

\section{Statistical Analysis}

Multiple logistic regression analysis was used to determine the role of variables at the initial survey in relation to worsening to diabetes during 7 years. Parameters were estimated by the method of Walker-Duncun [11]

\section{Results}

Table 2 shows the total number of subjects grouped by age, sex and glucose tolerance categories at the initial survey. The mean age \pm SEM of the subjects was $50.0 \pm 1.0$ years for the normal group, $57.4 \pm 2.0$ years for those with IGT and $55.6 \pm 2.1$ years for those found to be overtly diabetic. At the initial survey no treatment was recommended to the subjects with IGT, except for routine dietary instructions.

Table 3 gives the changes that occurred in glucose tolerance category of the subjects retested after 7 years. Of 161 subjects who were normal at the initial test, $15(9.3 \%)$ showed IGT, and seven $(4.3 \%)$ had become diabetic by the time of retest. Of 13 subjects who had IGT at the initial test, five (38.5\%) worsened to diabetes, while an equal number changed from IGT to normal after 7 years. Of 33 subjects who were diabetic at the initial test, five (15.2\%) reverted to impaired glucose tolerance or normal, but the remaining 28 $(84.8 \%)$ remained unchanged.

Table 4 shows the mean \pm SD of fasting and 2-h blood glucose levels at the initial and follow-up tests in relation to the initial glucose tolerance categories. The mean values tended to be elevated after the 7-year period in all three categories, implying a general dete-

Table 4. The mean fasting and $2 \mathrm{~h}$ blood glucose levels at the initial and follow-up oral glucose tolerance tests in the subjects who were retested after 7 years

\begin{tabular}{lccccc}
\hline Glucose tolerance at initial test & \multicolumn{2}{l}{ Fasting blood glucose $(\mathrm{mmol} / \mathrm{l})$} & & \multicolumn{2}{c}{2 h blood glucose $(\mathrm{mmol} / \mathrm{l})$} \\
\cline { 2 - 3 } & Initial test & Follow-up test & & Initial test & Follow-up test \\
\hline Normal $(n=161)$ & $5.1 \pm 0.6$ & $5.4 \pm 0.7$ & & $5.0 \pm 1.2$ & $5.6 \pm 2.4$ \\
Impaired glucose tolerance $(n=13)$ & $5.6 \pm 0.9$ & $6.9 \pm 3.5$ & & $9.0 \pm 0.9$ & $10.3 \pm 5.3$ \\
Diabetes $(n=33)$ & $10.2 \pm 5.3$ & $10.6 \pm 4.2$ & & $15.7 \pm 5.2$ & $16.6 \pm 5.9$ \\
\hline
\end{tabular}

Results expressed as mean $\pm \mathrm{SD}$ 
riorating trend in glucose tolerance over the follow-up period. This trend was most evident in the subjects with IGT, indicating about $23 \%$ elevation of the fasting level and about $15 \%$ elevation of the 2-h level after 7 years, though the variations of the blood glucose values at the retest were much greater than those at the initial test in this group.

Figure 1 shows a linear relationship between the rate of worsening to diabetes and the initial 2-h glucose levels in normal and IGT subjects. Those with a 2-h level greater than $8.9 \mathrm{mmol} / 1$ show a relatively high risk of worsening to diabetes compared with those with lower levels.

Further information on the relationship between variables at the time of the initial test (2-h glucose level, sex and obesity) and worsening to diabetes are shown in Table 5 . The rate of worsening from IGT to diabetes was $38.5 \%$ after 7 years, as mentioned above. In contrast, the rates were $0.8 \%$ and $14.1 \%$ for those with a $2-\mathrm{h}$ blood glucose $<6.1 \mathrm{mmol} / \mathrm{l}$ and those with 2-h blood glucose between 6.1-7.8 mmol/1, respectively. The rate of worsening to diabetes was significantly higher in the subjects with IGT and in subjects with a 2-h blood glucose between $6.1-7.8 \mathrm{mmol} / \mathrm{l}$ than in subjects with $2-\mathrm{h}$ blood glucose $<6.1 \mathrm{mmol} / 1$, but there was no significant difference between the rates in the former two groups. The overall rate of worsening to diabetes was $5.9 \%$ (males $11.1 \%$ and females $2.4 \%$ ), and was higher in obese than in non-obese subjects ( $15.6 \%$ and $4.5 \%$, respectively).

These relations were further examined by a multiple logistic regression analysis, using five factors as independent variables: sex, age, obesity, fasting glucose level and 2-h glucose level at the initial survey, as given in Table 6. There were significant relationships between worsening to diabetes and both the fasting and the 2-h glucose levels at the initial test, corresponding to the results in the univariate analysis. The coefficient for sex was also significant, indicating that risk of worsening to diabetes was greater in males than in females, as observed in the univariate analysis. On the other hand, the coefficient for obesity was slightly below the significant level in the multiple logistic regression analysis, although significant in the univariate analysis. No significant relationship was found between the rate of worsening and age.

\section{Discussion}

The term 'impaired glucose tolerance' has been used loosely in the past, often including borderline diabetes, early diabetes, chemical diabetes and so forth. All these terms were thought to refer to a state preceding overt diabetes, and a shift to the diabetic state was

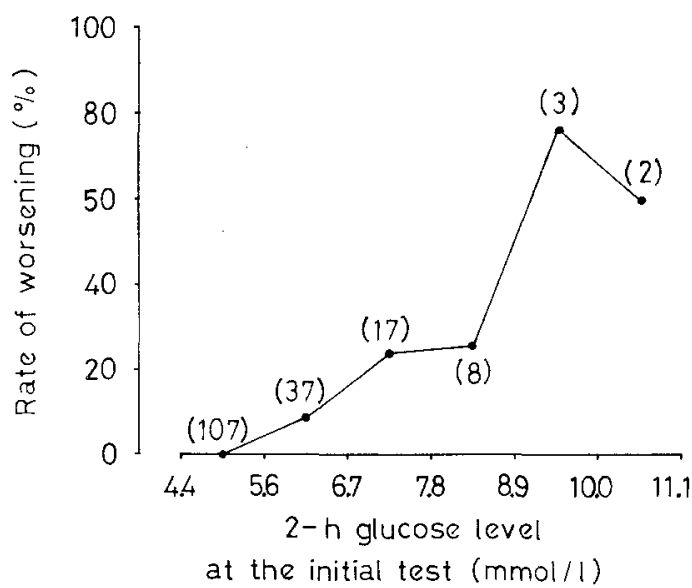

Fig. 1. Relation between the 2-h blood glucose level ( $\mathrm{mmol} / \mathrm{l})$ at the initial examination and the rate of worsening to diabetes after 7 years in subjects with normal and impaired glucose tolerance (fasting $<7.8$ and $2 \mathrm{~h}<11.1 \mathrm{mmol} / \mathrm{l}$ ). Numbers in parentheses indicate number of subjects in each blood glucose category at the initial survey

Table 5. Relationships between the rate of worsening to diabetes and 2 - $h$ blood glucose level, sex and obesity at the time of the initial survey

\begin{tabular}{|c|c|c|c|c|c|}
\hline \multicolumn{2}{|c|}{$\begin{array}{l}\text { Variables } \\
\text { at the initial test }\end{array}$} & \multirow{2}{*}{$\begin{array}{l}\text { No. of } \\
\text { subjects }\end{array}$} & \multirow{2}{*}{$\begin{array}{l}\begin{array}{l}\text { Subjects } \\
\text { developed } \\
\text { diabetes }\end{array} \\
1\end{array}$} & $\begin{array}{l}\text { Rate of } \\
\text { worsening } \\
(\%)\end{array}$ & $\begin{array}{l}p \\
\text { value }\end{array}$ \\
\hline $2 \mathrm{~h}$ & $<6.1$ & & & 0.8 ] & \\
\hline glucose & $6.1-7.8$ & 35 & 6 & $14.1^{\pi}$ & 0.01 \\
\hline$(\mathrm{mmol} / \mathrm{l})$ & $7.8-11.1$ & 13 & 5 & $38.5^{-}$ & 0.01 \\
\hline Males & & 90 & 10 & $11.1]$ & 0.05 \\
\hline Females & & 84 & 2 & $2.4^{\rfloor}$ & \\
\hline Non-obese & & 111 & 5 & 4.5 & \\
\hline Obese & & 45 & 7 & $15.6^{\rfloor}$ & 0.05 \\
\hline All cases & & 174 & 12 & 5.9 & \\
\hline
\end{tabular}

a Eighteen subjects were excluded because of insufficient data

Table 6. Standardized multiple logistic regression coefficients, standard errors and associated $t$-values for variables related to worsening to diabetes after 7 years

\begin{tabular}{lclc}
\hline Variables & Coefficient & SEM & $t$-value \\
\hline Sex & -1.43 & 0.61 & $-2.34^{\mathrm{a}}$ \\
Age & 0.08 & 0.55 & 0.15 \\
Obesity & 0.87 & 0.45 & 1.93 \\
Fasting glucose & 0.98 & 0.48 & $2.04^{\mathrm{a}}$ \\
2-h glucose & 1.73 & 0.49 & $3.55^{\mathrm{a}}$ \\
\hline
\end{tabular}

${ }^{a}$ significant at $5 \%$ level

assumed to be highly probable over a long-term period. Impaired glucose tolerance, or IGT, was first strictly defined by the new criteria for interpretation of the oral glucose tolerance test proposed by the 
WHO Expert Committee [1] and the NIH Diabetes Data Group [7].

As mentioned earlier, recent epidemiological studies have served to clarify the prognosis of IGT. In the Whitehall Survey [2], 27 of 204 men (13.2\%) with impaired glucose tolerance (or 'borderline diabetes') were found to worsen to diabetes during a 5-year follow-up period. In the Birmingham Diabetes Survey, $21.4 \%$ of 'glucose tolerance test diabetes' $(1 \mathrm{~h} \geqq 10.0$ and $2 \mathrm{~h} \geqq 7.5 \mathrm{mmol} / 1$ in capillary blood) changed to 'florid diabetes' (fasting glucose $\geqq 7.2 \mathrm{mmol} / \mathrm{l}$ ) over 5 years [3], and subsequently $45.2 \%$ of glucose tolerance test diabetes became florid diabetes over a 10 -year period. In this study, the rate of worsening was found to relate closely to the initial glucose value. $O$ 'Sullivan and Mahan [5] found the cumulative rate of developing diabetes to be $32 \%$ for 10 years among young patients with chemical diabetes, when the United States Public Health Service criteria were applied. Furthermore, Sartor et al. [6] reported that $29 \%$ of untreated male patients with impaired glucose tolerance developed diabetes over 10 years.

Since different definitions of IGT and worsening to diabetes were used in the studies cited above, it is not entirely appropriate to make direct comparisons between the results. The studies show, nonetheless, that those subjects who developed diabetes represent only a proportion of the subjects with IGT after a lenthy observation period. In the present study, the rate of worsening to diabetes after 7 years was $38.5 \%$ $(5.5 \% /$ year) for those with IGT and $22.9 \%$ (3.3\%/year) for those with 2 -h blood glucose values between $6.1-11.1 \mathrm{mmol} / \mathrm{l}$.

The present findings indicate that both the fasting and 2-h blood glucose level have a strong indicative power in relation to the subsequent development of diabetes. These findings confirm earlier reports in Caucasoids [2,3]. In addition, in the present study obesity was found to play a role in worsening to diabetes, although the predictive power of obesity was less than that of fasting and 2-h blood glucose levels.

Finally, it should be mentioned here that the follow-up rate was relatively low in this study; only $40.8 \%$ of the original subjects responded to the retest. Therefore, some bias might be introduced into the results. However, there were no significant differences in the distribution of initial age, sex, obesity, fasting and 2-h glucose levels between the original subjects and those who were retested. Furthermore, it should also be taken into account that the random variation of blood glucose values in oral glucose tolerance testing might influence the final results in this study because only one glucose tolerance test was performed at the follow-up survey. However, those who were retested after 7 years revealed an increase in the proportion of subjects with IGT or diabetes, and elevation of the mean fasting and 2-h blood glucose levels, providing evidence for a true overall trend of metabolic deterioration rather than mere random variation.

\section{References}

1. World Health Organization (1980) WHO Expert Committee on Diabetes Mellitus, Second Report. WHO Technical Report Series No646 pp 10-12

2. Jarrett RJ, Keen H, Fuller JH, McCartney M (1979) Worsening to diabetes in men with impaired glucose tolerance ('borderline diabetes'). Diabetologia 16:25-30

3. Birmingham Diabetes Survey Working Party (1970) Five-year follow-up report on the Birmingham Diabetes Survey of 1962. Br Med J 3: 301-305

4. Birmingham Diabetes Survey Working Party, (1976) Ten-year follow-up report on Birmingham Diabetes Survey of 1961 . Br Med J 2:35-37

5. O'Sullivan JB, Mahan CM (1968) Prospective study of 352 young patients with chemical diabetes. $N$ Engl J 27: 1038-1041

6. Sartor G, Schersten B, Carlstrom S, Nelandeer A, Norden A, Persson G (1980) Ten-year follow-up of subjects with impaired glucose tolerance. Prevention of diabetes by tolbutamide and diet regulation. Diabetes $29: 41-49$

7. National Diabetes Data Group (1979) Classification and diagnosis of diabetes mellitus and other categories of glucose tolerance. Diabetes 29: 1039-1057

8. Sasaki A, Suzuki T, Fujimoto I, Horiuchi N, Inui H (1971) A population-based epidemiological study on diabetes mellitus in a rural town. Characteristic features of diabetes in Japan. In: Tsuji S, Wada M (eds) Diabetes mellitus in Asia. Excerpta Medica, Amsterdam, pp 42-50

9. Sasaki A, Suzuki T, Horiuchi N (1980) Survival rate and causes of death in Japan. A 10-year follow-up study. J Chron Dis 33: 341-346

10. Minowa S, Takahashi S, Mayzumi N, Miyashita H(1962) Studies on the standard body weight for Japanese adults. Jpn Med J No. 1988:24-30

11. Walker SH, Duncan DB (1967) Estimation of probability of an event as a function of several independent variables. Biometrika 54: $167-179$

Received: 18 May 1981

and in revised form: 31 July 1981

Akira Sasaki M.D

Centre for Adult Diseases

3 Nakamichi 1-chome

Higashinari-ku

Osaka 537, Japan 